\title{
Differential fat harvesting
}

\author{
Sebastian Torres Farr'1, Angelo Trivisonno² \\ ${ }^{1}$ Department of Cranio Maxillofacial and Aesthetic Surgery, Clinica Santa Rita, 95124 Catania, Italy. \\ ${ }^{2}$ Department of Plastic Surgery, Sapienza University, 00185 Rome, Italy.
}

Address for correspondence: Dr. Sebastian Torres Farr, Via Monti Peloritani 2 C, 95030 Catania, Italy. E-mail: info@sebastiantorresmd.com

\begin{abstract}
Aim: Volume replacement with fillers is regularly performed with the use of diverse volumetric materials to correct different structures around the face, depending on the volume enhancement required and the thickness of the soft tissue envelope. Differential fat harvesting and posterior grafting is performed to place the correct fat parcel size for each target area, expanding the potential applications of fat. Methods: Sixty patients consecutively recruited on a first come basis undergone a facial fat grafting procedure, in private practice setting between March 2012 and October 2013. Fat grafting quantity and quality was predicted for each case. Differential harvesting was performed, with 2 fat parcels size. Processing was performed through washing. Fat infiltration was carried out through small cannulas or needles depending on the treated area. Outcomes were analysed both by the physicians and the patients at 7 days, 1 month, 3 months and 6 months through a perceived satisfaction questionnaire. Parameters considered were downtime or discomfort, skin benefits, volume restoration, reabsorption rate estimated and overall improvement. Results: Full facial differential fat grafting procedure lasted an average of 1.5-2.5 h. Average downtime was 3-4 days. Follow-up was performed to a minimum of 6 months. Both patient and physician overall satisfaction rates were mostly excellent. Adverse events like lumps or irregularities were not encountered. Conclusion: Differential fat harvesting and posterior grafting is a valid alternative, to expand the repertoire of fat use, allow a more homogeneous effect, reduce the potential complications, speed up the process, improve graft survival, and to enhance overall aesthetic outcome.
\end{abstract}

Key words:

Adipose stem cells, differential harvesting/grafting, facial fat grafting, mesofat, sharp needle intradermic fat grafting

\section{INTRODUCTION}

Volume replacement with fillers is regularly performed with the use of diverse volumetric materials to correct different areas around the face, depending on the volume enhancement required and the thickness of the soft tissue envelope that allows concealing the product.

Fat grafting, according to Coleman, ${ }^{11}$ has been traditionally done with tissue harvested with $2 \mathrm{~mm}$ port cannulas which only allows a gross correction of volume.

\begin{tabular}{|l|l|}
\hline \multicolumn{2}{|c|}{ Access this article online } \\
\hline Quick Response Code: & Website: \\
\hline & www.parjournal.net \\
\cline { 2 - 2 } & \\
\hline & DOI: \\
\hline
\end{tabular}

The former technique presents several limitations and complications especially in the lower eyelid region. ${ }^{[2]}$ In this area, the gross fat parcels cannot be hidden by a thin soft tissue envelope without risking overcorrection or lumps.

Micro fat grafting has been proposed as an option to bypass the former problems, and to extend the application of lipostructure to the superficial layers of the skin. ${ }^{[3]}$ However, this is time consuming and inefficient in volume restoration. Moreover, harvesting through small hole cannulas can affect the integrity of adipocytes. ${ }^{[4,5]}$

Fat processing is another key factor in fat grafting, which allow us to get rid of all the toxic and inflammatory agents that may affect graft retention. Centrifuging, washing and decanting have been proposed as valid alternatives. Nevertheless, recent data suggest that strong centrifugation can damage adipose graft integrity and decanting is not able to get rid of the oil vacuoles present within the graft. Washing, therefore, remains as the single most important phase in fat processing. ${ }^{[6]}$ The same authors have proposed 
a soft centrifugation $(400 \mathrm{~g} / \mathrm{L} \min [1,000 \mathrm{rpm} / \mathrm{L} \mathrm{min}])$ as an alternative following washing of the graft.

Both traditional fat grafting and micro fat grafting have pros and cons. Differential fat harvesting is performed in an attempt to obtain the correct fat parcel size for each target area, expanding the potential uses of fat, and allowing for superior homogeneity and aesthetics.

\section{METHODS}

Sixty consecutively recruited patients underwent facial fat grafting, between March 2012 and October 2013 in private practice setting. The procedure was explained in detail and informed consents and ethical statements were signed for each case.

A Torres facial fat grafting record was used to predict the quantity and quality of the fat to be used in each case [Figure 1].

Facial fat consumption was estimated taking into consideration:

1. Fat to be placed in critical areas (periorbital, temples, lips, nasal)

2. Fat for needle placement prediction (sharp needle intradermic fat [SNIF] grafting or mesofat technique) ${ }^{[7,8]}$

3. Fat for adipose stem cell (ASC) enhancement estimation

4. Fat for volume enhancement in the rest of the face.

Super wet infiltration of the donor site was performed with a low dose of lidocaine solution (maximum $20 \mathrm{~mL}$ lidocaine $2 \%$ in $500 \mathrm{~mL}$ saline), trying to infiltrate an equal volume of liquid compared to the volume of fat to be removed..$^{[9]}$

Following the record, the differential harvesting concept was applied, where fat was extracted in two different manners.

Thin fat parcels (i-iii) were extracted manually with a six port $(0.8 \mathrm{~mm}$ each) Tulip Tonnard harvesting $2 \mathrm{~mm}$ width $\times 15 \mathrm{~cm}$ length cannula (Tulip medical, San Diego, CA) coupled to a $20 \mathrm{~mL}$ syringe.

Thick fat parcels (iv) are automatically extracted with a Shippert four port ( $5 \mathrm{~mm} \times 2 \mathrm{~mm}$ each) harvesting $3 \mathrm{~mm}$

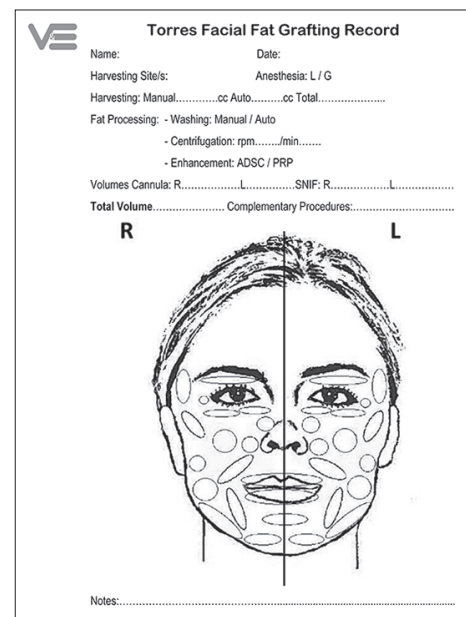

Figure 1: Torres fat grafting module. It helps to estimate pre operatory fat volumes and type of fat needed for each case, that will command the differential harvesting and posterior grafting width $\times 15 \mathrm{~cm}$ length cannula (Shippert medical, Denver, $\mathrm{CO})$ connected to a biplane luerlok handle attached to a $250 \mathrm{~mL}$ Filtron Unit (Shippert Medical, Denver, CO) linked to an surgical aspirator.

Fat processing was performed through washing in a closed manner with the aid of Filtron device for the thick fat and manually in an open system for the thin fat extracted.

Facial regional blocks were performed with mepivacaine prior to infiltration phase.

Thin fat parcel infiltration was carried out through $0.9 \mathrm{~mm} \times 5 \mathrm{~cm}$ Tulip injector cannula (Tulip medical, San Diego, CA) in critical areas (temples, periorbital, lips, and nasal) or with needles; $23 \mathrm{G} \times 30 \mathrm{~mm}$ in SNIF or $27 \mathrm{G} \times 4 \mathrm{~mm}$ in Mesofat technique. Needle was placed in superficial wrinkles and lines, to enhance corrections at an intradermal plane for deep folds, and in cases of strong photo and chrono aging (Mesofat).

When available ASCs filter Mystem (Bimedica SRL, BG, Italy) was used in combination with fine parcel fat to obtain ASC enhanced serum to be mixed with fat prior to infiltration.

Thick fat parcels were infiltrated using a $1.2 \mathrm{~mm} \times 7 \mathrm{~cm}$ Tulip cannula in all the other parts of the face. This placement was favoured whenever the primary goal was volumetric enhancement and when soft tissue envelope was thick.

The amount and type of fat injected in each area is summarized in Table 1.

Parameters analysed were downtime and discomfort, skin benefits, volumetric enhancement, reabsorption rate, and overall improvement, all of which were recorded using a patient satisfaction questionnaire [Table 2], applied at 7 days, 1 month, 3 months and 6 months. Satisfaction scores were considered as excellent (15-20 points), good (10-14 points), minor (5-9 points) and poor $(<5$ points). Statistical analysis was performed in Excel 2013.

Table 1: Amount and type of fat injected per area

\begin{tabular}{lcc}
\hline Area & $\begin{array}{l}\text { Type of } \\
\text { fat }\end{array}$ & $\begin{array}{c}\text { Amount of fat } \\
\text { injected (mL) }\end{array}$ \\
\hline Eyebrow & Thin fat & $1^{*}$ \\
Temples & & $2^{*}$ \\
Lower palpebral medial & $1^{*}$ \\
Lower palpebral lateral & $1^{*}$ \\
Lateral canthus & & $0.3^{*}$ \\
Lips & 3 \\
SNIF (glabella, lips and NLF) & Thick fat & 2 \\
Zygoma & & $2-3^{*}$ \\
Malar & & $2^{*}$ \\
Buccal & & $3^{*}$ \\
NLF & & $1^{*}$ \\
Canine fossa & $1^{*}$ \\
Labiomental fold & & $1.5^{*}$ \\
Mental crease & $1^{*}$ \\
Total per side & 21.8 \\
Total for full face approach & & 43.6 \\
\hline
\end{tabular}

*Per side. SNIF: Sharp needle intradermic fat, NLF: Nasolabial fold 


\section{RESULTS}

The study included, 48 women (age range: 37-58 years, mean: 49 years) and 12 men (age range: 32-34 years, mean: 33 years).

Full facial differential fat grafting procedure last between 1.5 and $2.5 \mathrm{~h}$, and was performed under local anaesthesia and minor sedation in the majority.

Average volume harvested manually was $21 \mathrm{~mL}$ (mean: $21 \mathrm{~mL}$; median: $21.5 \mathrm{~mL}$; standard error: $0.61 \mathrm{~mL}$; range: $18 \mathrm{~mL}$ ) (of fine parcels fat) and automatically $35 \mathrm{~mL}$ (mean: $35.02 \mathrm{~mL}$; median: $35 \mathrm{~mL}$; standard error: $0.635 \mathrm{~mL}$; range: $25 \mathrm{~mL}$ ) (of thick parcels fat). Average fat infiltrated was $45 \mathrm{~mL}$ (mean: $45.14 \mathrm{~mL}$; median: $45 \mathrm{~mL}$; standard error: $0.995 \mathrm{~mL}$; range: $35 \mathrm{~mL}$ ).

Harvesting sites were: abdominal (50\%), outer thighs (20\%), back $(10 \%)$, triceps $(10 \%)$, inner thighs, and knee $(10 \%)$.

ASC filter was used only in six cases, which did not allow us to statistically analyse the data.

Table 2: Patient satisfaction questionnaire, for satisfaction assessment at 7 days, 1 month, 3 months and 6 months

\begin{tabular}{|c|c|}
\hline Parameter evaluated & Score \\
\hline \multicolumn{2}{|l|}{ Downtime or discomfort } \\
\hline No downtime or discomfort & 4 \\
\hline Very slight discomfort (downtime 24 h) & 3 \\
\hline Average discomfort (downtime $2-5$ days) & 2 \\
\hline Moderate to severe discomfort (downtime 5-10 days) & 1 \\
\hline Severe discomfort (downtime $>10$ days) & 0 \\
\hline \multicolumn{2}{|l|}{ Skin benefits } \\
\hline Excellent (improves in tone, elasticity and texture) & 4 \\
\hline Moderate improvement & 3 \\
\hline Slight improvement & 2 \\
\hline None & 1 \\
\hline Worsening of skin quality (acne lesions, scars, etc.,) & 0 \\
\hline \multicolumn{2}{|l|}{ Volume restoration outcome } \\
\hline Very satisfied & 4 \\
\hline Moderately satisfied & 3 \\
\hline Slightly satisfied & 2 \\
\hline Not satisfied & 1 \\
\hline Dissatisfied (important over or under corrections) & 0 \\
\hline \multicolumn{2}{|l|}{ Reabsorption rate estimated (\%) } \\
\hline $0-20$ & 4 \\
\hline $20-30$ & 3 \\
\hline $30-50$ & 2 \\
\hline $50-70$ & 1 \\
\hline$>70$ & 0 \\
\hline \multicolumn{2}{|l|}{ Overall evaluation } \\
\hline Very satisfied & 4 \\
\hline Moderately satisfied & 3 \\
\hline Slightly satisfied & 2 \\
\hline Not satisfied & 1 \\
\hline Dissatisfied (important overcorrections or under corrections) & 0 \\
\hline Total possible score for fat grafting procedure & 20 \\
\hline
\end{tabular}

Satisfaction was defined as: excellent (20-15 points), good (14-10 points), minor ( $9-5$ points), and scarse ( $<5$ points)
Average downtime was 3-5 days, with minimum to moderate inflammation.

Follow-up was performed for a minimum of 6 months (range: 6-12 months) [Figures 2-4].

Satisfaction questionnaires showed high test scores at 5 days (mean: 16.42, standard error: 0.26, median: 16, mode: 15, and standard deviation: 1.93). Slight descent trend in the test scores were seen at 6 months (median: 16, standard error: 0.29, median: 16, mode: 16, and standard deviation: 2.1). Global patient test scores and trend lines are shown in Figure 5. Satisfaction scores evaluations were defined as excellent $89 \%(n=193)$, good $8.8 \%(n=19)$, minor $1.85 \%(n=4)$.

Adverse events like lumps or irregularities were not evidenced.

Dissatisfaction was referred by 2 patients for under correction in the buccal region (1 patient) and temporal area (1 patient).

Skin improvements were mild to moderate and were often referred spontaneously by the patients.

Both patient and physician satisfaction rate was excellent in $81.5 \%(n=44)$ of the cases.

\section{DISCUSSION}

Traditionally Coleman lipostructure has promoted fat harvesting with $2 \mathrm{~mm}$ port cannulas, followed by a strong centrifugation $(3,000 \mathrm{rpm}$ for $3 \mathrm{~min})$, removal of the supra and infranadant, and final reinfiltration with the aid of $16 \mathrm{G}$ cannulas. ${ }^{[1]}$ The former has permitted to achieve gross good aesthetic improvements with long lasting results. Nevertheless, extensive discomfort and healing time (15 days), unpredictable reabsorption, need of overcorrections, frequent retouches and lower lid complications $^{[2]}$ have made the technique less attractive for patients and physicians. Therefore, efforts have been made to find a more predictable and forgiving technique.
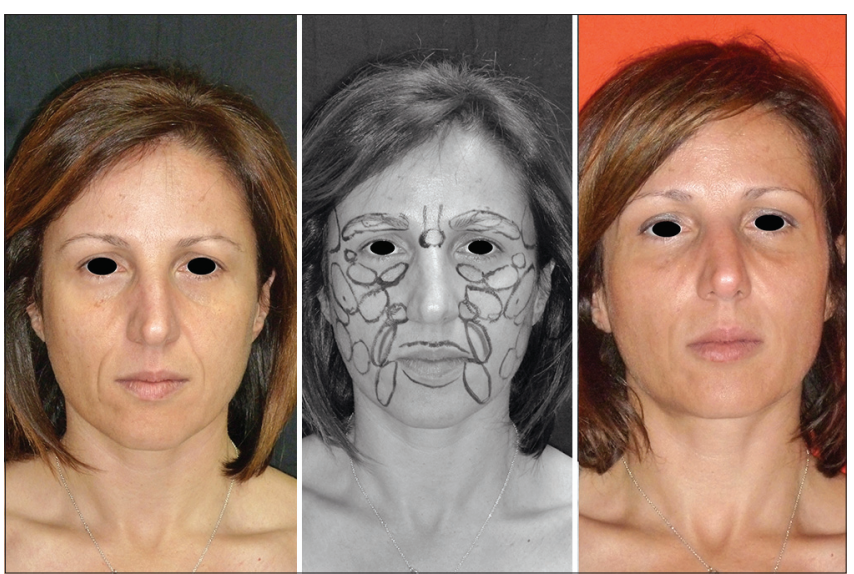

Figure 2: Clinical case 1. Patient before, intra operatory design, and 6 months postoperative 
According to Eto et al., ${ }^{[10]}$ micro fat lobules are easy to inject, have a greater three-dimensinal cellular interaction and generate less nodules or bumps incidence. Moreover they have greater versatility of use, being placed using cannulas or needles and in different anatomical planes (subcutaneous or intradermal). Recently, it has been proposed that greater tissue disruption obtained with smaller cannulas has been associated with higher amount of ASC in the lipoaspirate, especially of the superficial layers of fat. ${ }^{[1]}$

Indications for thin fat parcels harvesting include: the treatment of facial critical areas of delicate skin with thin soft tissue envelope (like periorbital, temporal and perioral regions), the delivery of fat through needles (SNIF or Mesofat techniques), ${ }^{[7,8]}$ main treatment goal to be skin regeneration, and the use of fat for ASC enhancement through filters.

Nevertheless their extraction is much slower than traditional harvesting. Furthermore, reduced diameter or ports from harvesting cannulas generate greater adipose cells stress, cellular breakdown and oil content in the harvested tissue, resulting in less viable adipose cells, with greater necessity of fat processing (washing or centrifugation) [Figure 6]. ${ }^{[4,5]}$

All above, has put micro lipofilling into fashion, increasing
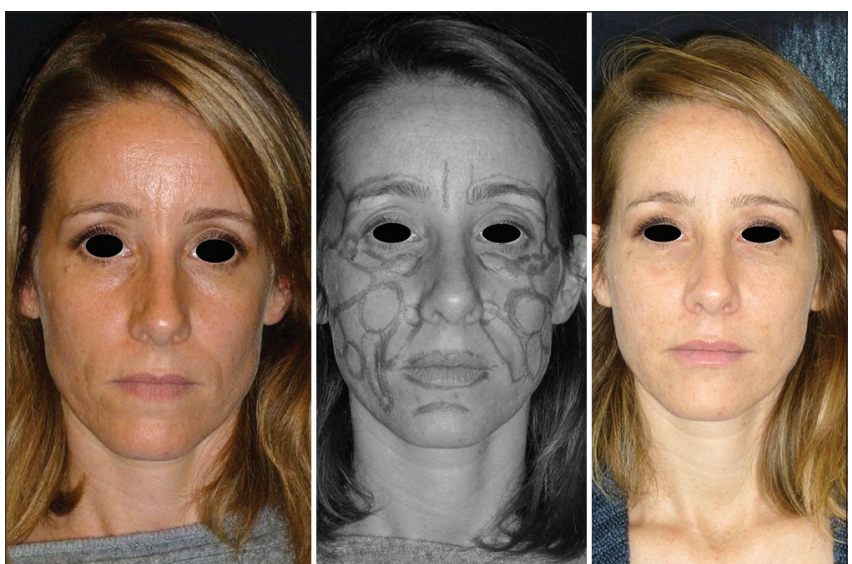

Figure 3: Clinical case 2. Patient before, intra operatory design, and 6 months postoperative

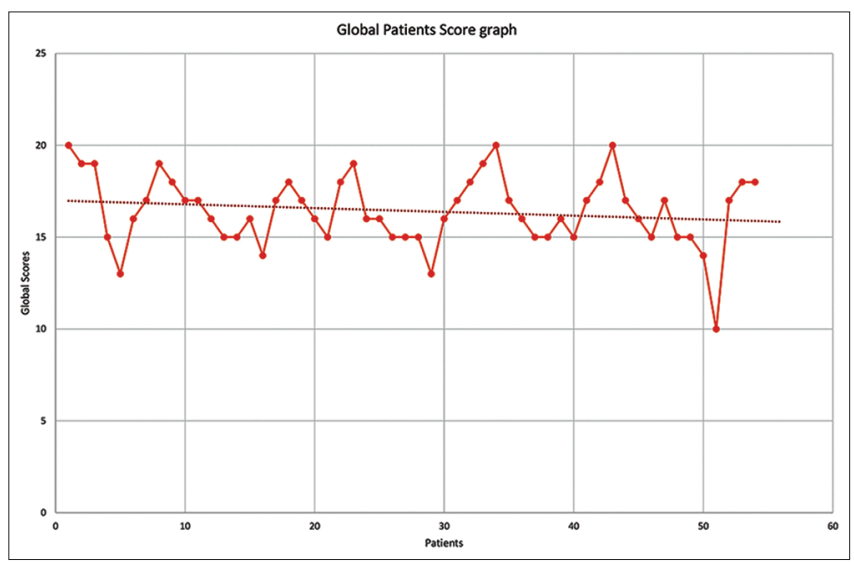

Figure 5: Global patient scores graph on satisfaction questionnaire and trend line its popularity and interest in the medical community. It has also created greater confusion widening the possible range of variables regarding fat grafting. This has been reflected in recent publications that try to obtain a recipe for the correct technique. ${ }^{[12]}$

The goals of a fat grafting treatment are: volume restoration and skin regeneration. Volume is determined mainly by the adipocytes, and the process known as primary adipocyte integration should be considered a primary goal within the treatment.

Cellular regeneration, is principally explained by the presence of ASC in the lipoaspirate. It is an important event, but it is not the only factor involved.

Cannulas port size affects directly the adipocytes. The larger the aspiration cannula, the greater the viscosity, retention and quality of the graft. ${ }^{[4,5]}$

On the other hand the smaller the cannula size, the lesser the viscosity, and higher tissue disruption, oil content and amount of ASC within the graft [Figure 7]. A fluid grafts allows needle or fine cannula placement and avoids irregularities in critical areas.

In this context, the concept of differential harvesting is raised.

The term differential fat harvesting stands for fat harvesting through different cannulas (port sizes or
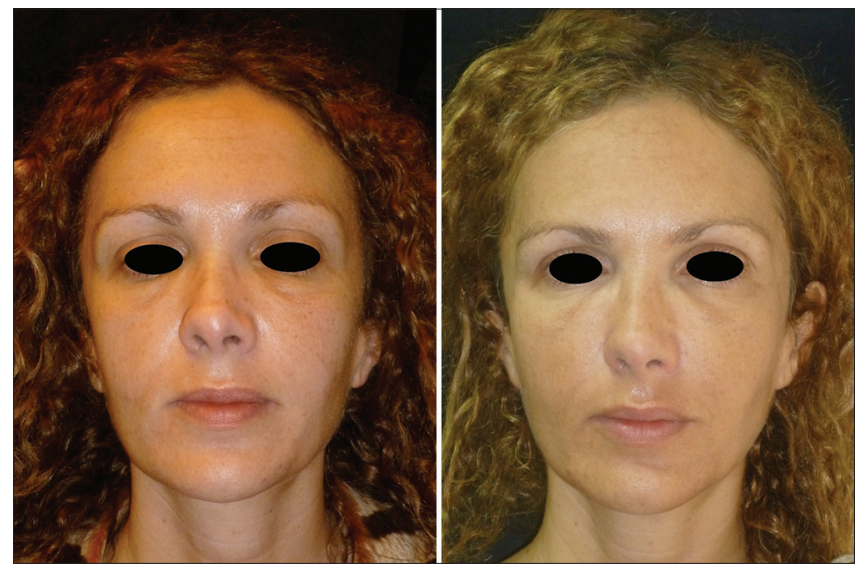

Figure 4: Clinical case 3. Patient before and 12 months postoperative

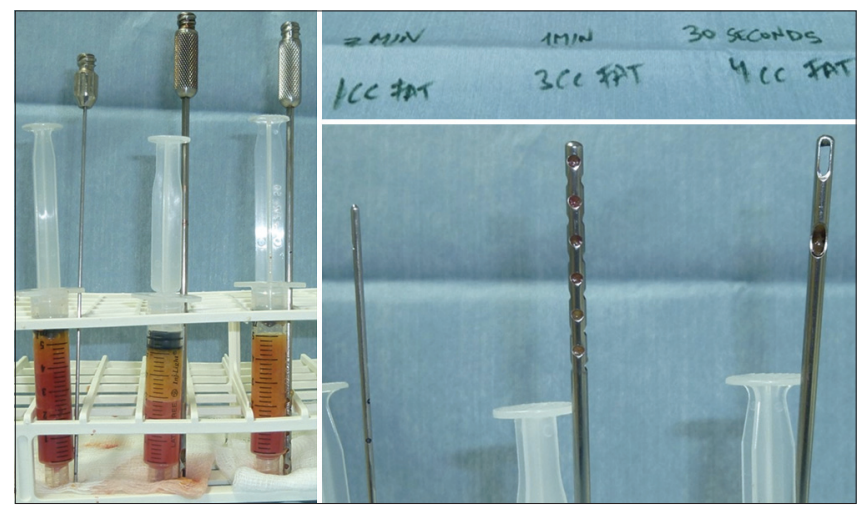

Figure 6: Different cannula port sizes and time needed for harvesting and amount of fat and oil extracted 
diameter) based on the placement area, technique to be used, or intended cellular population.

This technique allows to obtain different sizes of fat parcels and to perform a differential fat grafting, to gain as much as possible from each individual treatment goal, volume restoration and skin regeneration, for greater patient and surgeon satisfaction. ${ }^{[1]}$

The benefits of the differential harvesting are versatility of fat, more precise corrections, and achiving homogeneous results.

It improves fat survival in critical spots and reduces the overall fat oil content resulting in reduced inflammation and downtime for patients.

Furthermore it may reduce the potential complications, and speed up the whole process.

Moreover it allows us to obtain different extraction samples to be processed or enhanced in different ways.

In areas of great muscular mechanical stress, a fact known as an important factor determining early absorption of fillers, ${ }^{[13]}$ it allows multiplane corrections (intradermal, subcutaneous, and supraperiosteal) permitting to obtain a better volumetric survival, because we do not overcorrect on one plane, we expand all of them in a manner that the transplanted cells may establish new circulatory connections and posterior survival.

The other important factor is the dead space created in the infiltrative phase. The bigger the cannulas, the more important the trauma becomes as the dead space to be filled with serum on the scarring tissue will interfere in cell integration. By having different adipose parcel sizes, small cannulas and needles can be used for delivery, reducing the trauma and dead space in the healing phase. The lesser the inflammation the closer the transplanted cells will be to the vessels.

Finally it is well known that whatever the ASC does relies mainly on the cellular niche or immediate micro ambient surrounding. ${ }^{[14]}$ Cellular niche is different in the intradermal, subcutaneous and supra periosteal plane, so

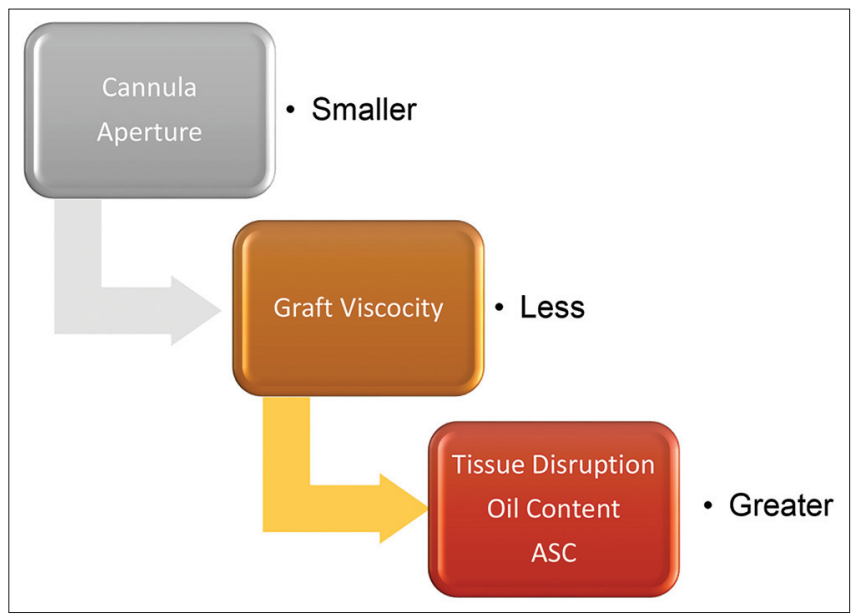

Figure 7: Diagram relation between cannula port - width size and tissue disruption, oil content and adipose stem cell we can expect different actions from this cells depending on the plane transplanted.

Differential fat harvesting and posterior differential grafting is a valid alternative, to expand the repertoire of fat use, allow a more homogeneous effect, reduce the potential complications, speed up the process, improve graft survival, and enhance overall aesthetic outcome.

The mastery of this technical modifications, which affect our graft, together with the understanding of recipient site $^{[15-17]}$ and systemic factors, will allow us to get long lasting and reproducible results for the benefit of our patients.

\section{REFERENCES}

I. Coleman SR. Facial augmentation with structural fat grafting. Clin Plast Surg 2006;33:567-77.

2. Coleman SR. Lower lid deformity secondary to autogenous fat transfer: a cautionary tale. Aesthetic Plast Surg 2008;32:4I5-7.

3. Nguyen PS, Desouches C, Gay AM, Hautier A, Magalon G. Development of micro-injection as an innovative autologous fat graft technique: the use of adipose tissue as dermal filler.J Plast Reconstr Aesthet Surg 2012;65: I692-9.

4. Kirkham JC, Lee JH, Medina MA $3^{\text {rd }}$, McCormack MC, Randolph MA, Austen WG Jr.The impact of liposuction cannula size on adipocyte viability. Ann Plast Surg 20I2;69:479-8I.

5. Erdim M, Tezel E, Numanoglu A, Sav A. The effects of the size of liposuction cannula on adipocyte survival and the optimum temperature for fat graft storage: an experimental study. J Plast Reconstr Aesthet Surg 2009;62:1210-4.

6. Hoareau L, Bencharif K, Girard AC, Gence L, Delarue P, Hulard O, Festy F, Roche R. Effect of centrifugation and washing on adipose graft viability: a new method to improve graft efficiency. J Plast Reconstr Aesthet Surg 2013;66:712-9

7. Zeltzer AA, Tonnard PL, Verpaele AM. Sharp-needle intradermal fat grafting (SNIF). Aesthet Surg J 2012;32:554-6I.

8. Farr ST. SNIF and Mesofat for neck and décolleté rejuvenation. Presented at the World Congress of Facial Plastic Surgery, Rome, Italy; 2012.

9. Girard AC, HivernaudV, Gauthier J, Festy F, Roche R. Lipoflling: Critical points of successful fat transplantation.J Ästhet Chir 2014;7:93-7. (in German)

10. Eto $H$, Kato $H$, Suga $H$, Aoi N, Doi K, Kuno S, Yoshimura $K$. The fate of adipocytes after nonvascularized fat grafting: evidence of early death and replacement of adipocytes. Plast Reconstr Surg 2012;129:1081-92.

II. Trivisonno A, Di Rocco G, Cannistra C, Finocchi V, Torres Farr S, Monti M, Toietta G. Harvest of superficial layers of fat with a microcannula and isolation of adipose tissue-derived stromal and vascular cells. Aesthet Surg J 20I4;34:60I-I3.

12. Kakagia D, Pallua N. Autologous Fat Grafting: in Search of the Optimal Technique. Surg Innov 2014;21:327-36.

13. Torres S. Injectable skin fillers adverse effects. Rev Ital Med Estado 2009;33:395-420.

14. Chen S, Lewallen M, Xie T. Adhesion in the stem cell niche: biological roles and regulation. Development 20I3; |40:255-65.

15. Kato H, Mineda K, Eto H, Doi K, Kuno S, Kinoshita K, Kanayama K, Yoshimura K. Degeneration, regeneration, and cicatrization after fat grafting: dynamic total tissue remodeling during the first 3 months. Plast Reconstr Surg 2014;133:303e-13e.

16. Baek RM, Park SO, Jeong EC, Oh HS, Kim SW, Minn KW, Lee SY.The effect of botulinum toxin A on fat graft survival. Aesthetic Plast Surg 2012;36:680-6.

17. Sezgin B, Ozmen S, Bulam H, Omeroglu S, Yuksel S, Cayci B, Peker T. Improving fat graft survival through preconditioning of the recipient site with microneedling. J Plast Reconstr Aesthet Surg 20 |4;67:7| 2-20.

How to cite this article: Farr ST, Trivisonno A. Differential fat harvesting. Plast Aesthet Res 2014;1:103-7.

Source of Support: Nil, Conflict of Interest: None declared.

Received: 12-03-2014; Accepted: 17-07-2014 